\title{
TWO CRITERIA FOR UNIVALENCY
}

\author{
N. SAMARIS \\ Department of Mathematics \\ University of Patras \\ Patras 26110, Greece \\ (Received January 11, 1994 and in revised form February 28, 1995)
}

ABSTRACT. In the present paper we give two criteria for the functions $f(z)=z+\alpha_{2} z^{2}+\ldots$ to be univalent in $|z|<1$

KEY WORDS AND PHRASES. Univalent functions, univalency. 1990 MATHEMATICS SUBJECT CLASSIFICATION. Primary 30C45.

Let $A$ denote the class of functions which are analytic in the unit disk $U=\{z:|z|<1\}$ and $f^{\prime}(0)-1=0$. By $B$ we denote the class of functions $f \in A$ which are univalent, convex and bounded in $L^{\prime}$. In the present paper we prove the following theorems.

THEOREM 1 . Let $f \in A$, satisfy the condition

$$
! \frac{q_{0}^{2}}{q^{\prime}}\left[\frac{z^{2} f^{\prime}}{f^{2}}-\frac{z^{2} q^{\prime}}{q^{2}}\right] ! \leq 1 \text { in } U
$$

for some $q \in B$, where $q_{0}=\sup \{|q(z)| ; z \in U\}$. Then $f$ is univalent in $U$.

THEOREM 2. Let $f \in A, q \in B$ satisfy the condition

$$
\left|\frac{1}{q^{\prime}}\left[\frac{z}{f(z)}-\frac{z}{q(z)}\right]\right| \leq \lambda \text { in } U,
$$

for some $q \in B$, where

$$
\lambda=\imath n f\left\{\left|\frac{q^{\prime}(z)}{q_{0}^{2} q(z)}\right| ; i \in U\right\} .
$$

Then $f$ is univalent in $U$.

If we put $q(z)=z$ in the Th.1 we get the Ozaki and Nunokawa theorem [2].

If we put $q(z)=z$ in the Th.2 we get the Nunokawa,Obradovic and Owa theorem [1].

PROOF OF THEOREM 1 . If

$$
\phi=\frac{q_{0}^{2}}{q^{\prime}}\left[\frac{f^{\prime}}{f^{2}}-\frac{q^{\prime}}{q^{2}}\right]
$$

then $\phi$ is analytic in $U$ and

$$
-\frac{1}{f(z)}+\frac{1}{q(z)}=\frac{1}{q_{0}^{2}} \int_{0}^{z} q^{\prime}(\omega) \phi(\omega) d \omega+c .
$$

If we put $q(\omega)=\xi$ we get

$$
-\frac{1}{f(z)}+\frac{1}{q(z)}=\frac{1}{q_{0}^{2}} \int_{0}^{q(z)} \phi\left(q^{-1}(\xi)\right) d \xi+c
$$


From the condition $q \in B$ and the relation (3) we get

$$
\frac{1}{f\left(z_{1}\right)}-\frac{1}{f\left(z_{2}\right)}+\frac{1}{q\left(z_{2}\right)}-\frac{1}{q\left(z_{1}\right)}=\frac{1}{q_{0}^{2}} \int_{q\left(z_{1}\right)}^{q\left(z_{2}\right)} \phi\left(q^{-1}(\xi)\right) d \xi
$$

From Schwarz's Lemma and condition (1) we get $\phi(z) \mid \leq 1$ in $U$. Now from the relation (4) we get

$$
\left|\frac{1}{f\left(z_{1}\right)}-\frac{1}{f\left(z_{2}\right)}+\frac{1}{q\left(z_{2}\right)}-\frac{1}{q\left(z_{1}\right)}\right| \leq \frac{\left|q\left(z_{1}\right)-q\left(z_{2}\right)\right|}{q_{0}^{2}}
$$

If $f\left(z_{1}\right)=f\left(z_{2}\right)$ then it is obvious that $q\left(z_{1}\right)=q\left(z_{2}\right)$ or $z_{1}=z_{2}$.

PROOF OF THEOREM 2. If we put

$$
P(z)=\frac{z^{2} f^{\prime}}{f^{2}}-\frac{z^{2} q^{\prime}}{q^{2}}
$$

then we get

$$
P^{\prime}(z)=-z\left[\frac{z}{f(z)}-\frac{z}{q(z)}\right]^{\prime \prime} \text { and } \frac{\left|P^{\prime}(z)\right|}{\left|q^{\prime}(z)\right|} \leq \lambda \text { in } U
$$

From the relation

$$
P(z)=\int_{0}^{q(z)} \frac{P^{\prime}\left(q^{-1}(\xi)\right)}{q^{\prime}\left(q^{-1}(\xi)\right)} d \xi
$$

we get

$$
|P(z)| \leq \lambda|q(z)| \text { in } U .
$$

Now, the condition (1) of Th.1 is obvious.

\section{REFERENCES}

1. NUNOKAWA, M., OBRADOVIC, M. and OWA, S. One criterion for univalency. Proc. Amer. Math. Soc. 106 (1989) 1035-1037.

2. OZAKI, S. and NUNOKAWA, M. The Scharzian derivative and univalent functions, Proc. Amer. Math. Soc. 33 (1972),392-394." 


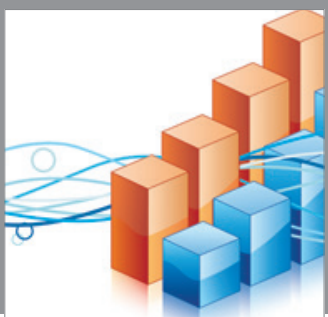

Advances in

Operations Research

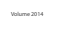

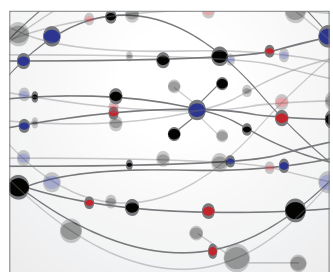

\section{The Scientific} World Journal
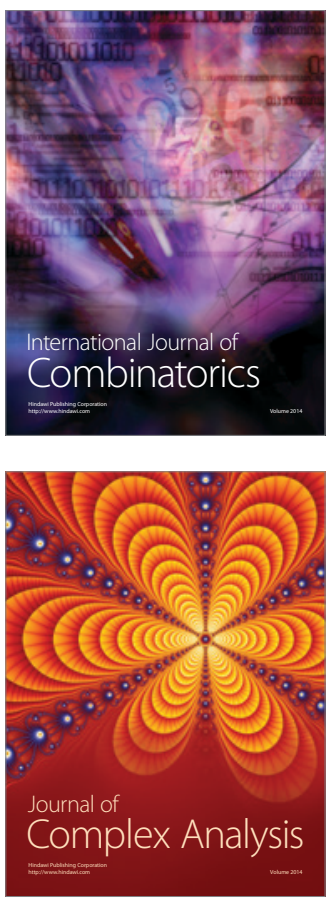

International Journal of

Mathematics and

Mathematical

Sciences
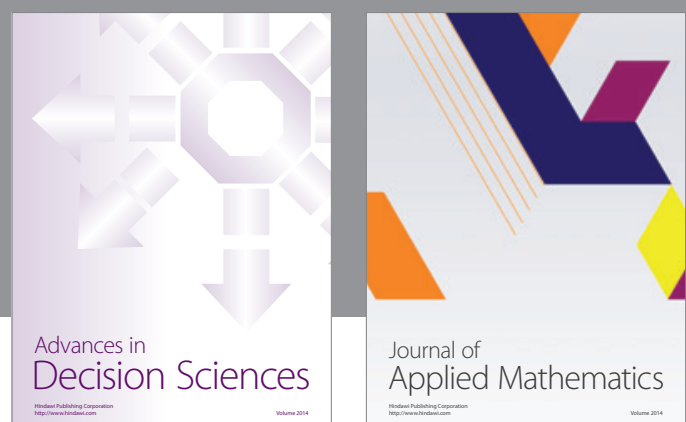

Journal of

Applied Mathematics
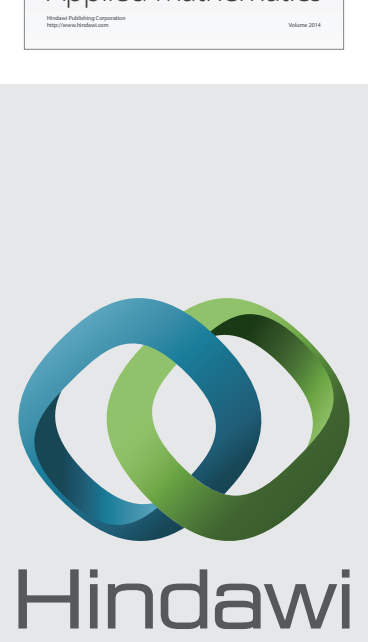

Submit your manuscripts at http://www.hindawi.com
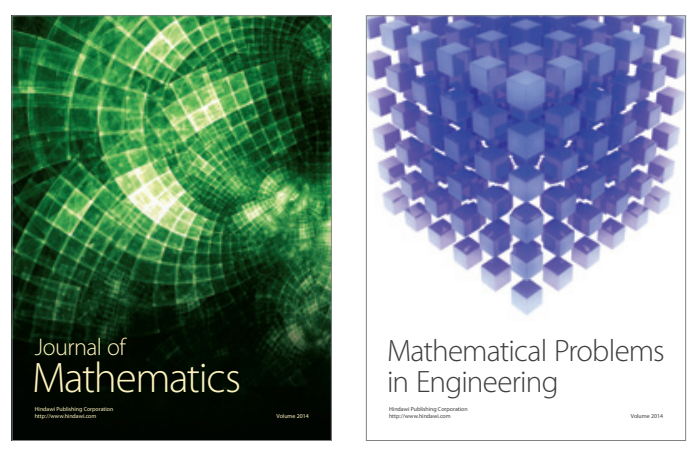

Mathematical Problems in Engineering
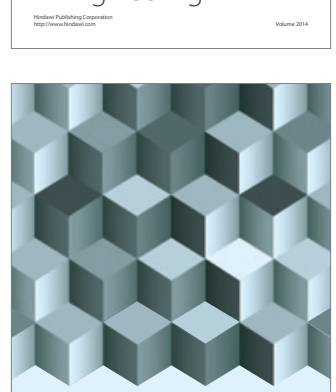

Journal of

Function Spaces
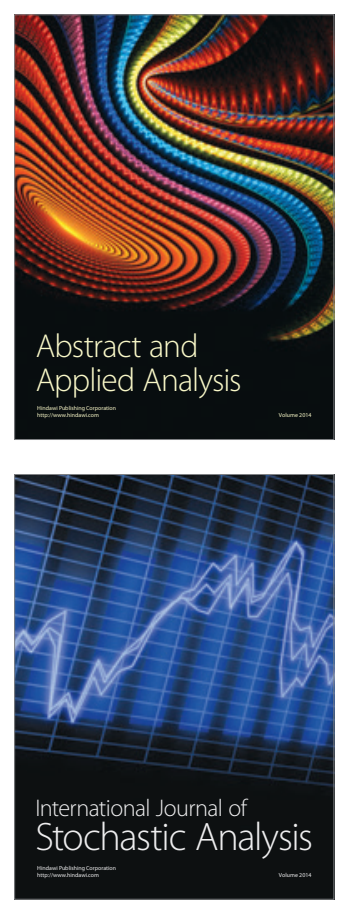

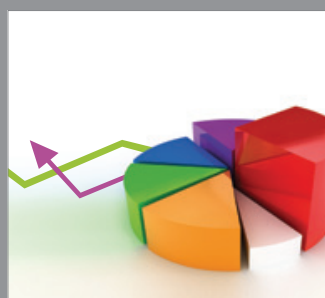

ournal of

Probability and Statistics

Promensencen
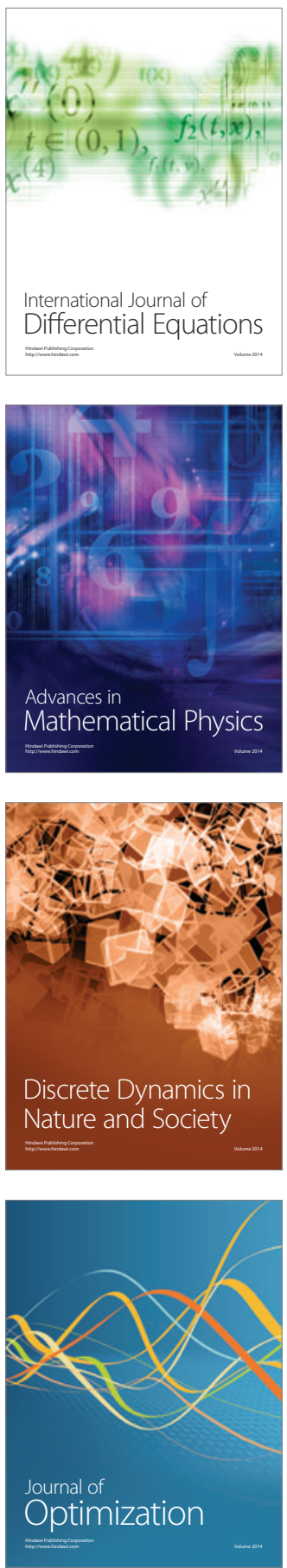